\title{
FIBCD1 overexpression predicts poor prognosis in patients with hepatocellular carcinoma
}

\author{
YAN WANG $^{1 *}$, MENGJING SUN $^{2,3^{*}}$, JIBIN LIU $^{4}$, YING LIU $^{1}$, CHUNYI JIANG ${ }^{1}$, \\ HUIJUN ZHU ${ }^{1}$, WEI WANG ${ }^{1}$ and YAO WANG ${ }^{5}$
}

\begin{abstract}
Departments of ${ }^{1}$ Pathology and ${ }^{2}$ Clinical Biobank, Affiliated Hospital of Nantong University; ${ }^{3}$ Department of Pathology, School of Medicine, Nantong University, Nantong, Jiangsu 226001; ${ }^{4}$ Department of Tumor Biobank, Nantong Tumor Hospital, Nantong, Jiangsu 226361; ${ }^{5}$ Department of General Surgery, Affiliated Hospital of Nantong University, Nantong, Jiangsu 226001, P.R. China
\end{abstract}

Received June 3, 2019; Accepted November 1, 2019

DOI: $10.3892 / \mathrm{ol} .2019 .11183$

\begin{abstract}
Fibrinogen C domain-containing 1 (FIBCD1) is an acetyl-recognition receptor that affects the occurrence and development of certain tumors. However, the prognostic significance of FIBCD1 in hepatocellular carcinoma (HCC) remains unclear. This study aimed to explore FIBCD1 expression in $\mathrm{HCC}$ and to determine the prognostic value of FIBCD1 in patients with HCC. A total of 1,058 liver tissue samples with detailed and complete clinical information were collected, including 495 HCC samples. Tissue microarray immunohistochemistry analysis was used to evaluate FIBCD1 protein expression in the collected tissues. The Kaplan-Meier plotter online tool was used to investigate the association between FIBCD1 expression and prognosis of patients with HCC. Oncomine and the Gene Expression Profiling Interactive Analysis database were used for bioinformatics analysis of FIBCD1. Results showed that FIBCD1 expression was higher in HCC and was associated with tumor diameter $(\mathrm{P}=0.002)$, tumor number $(\mathrm{P}=0.001)$, tumor node metastasis stage $(\mathrm{P}<0.001)$, primary tumor $(\mathrm{T} ; \mathrm{P}<0.001)$, lymph node metastases $(\mathrm{N} ; \mathrm{P}=0.002)$, distant metastases $(\mathrm{M} ; \mathrm{P}=0.023)$, differentiation degree $(\mathrm{P}=0.003)$, vascular invasion $(\mathrm{P}<0.001)$ and liver cirrhosis $(\mathrm{P}=0.011)$. Patients with $\mathrm{HCC}$ and high FIBCD1 expression had worse overall survival than those with low FIBCD1 expression. High FIBCD1 expression $(\mathrm{P}<0.001)$, TNM stage $(\mathrm{P}=0.003), \mathrm{T}(\mathrm{P}<0.001), \mathrm{N}(\mathrm{P}=0.014)$, and vascular invasion $(\mathrm{P}<0.001)$ were independent prognostic factors in
\end{abstract}

Correspondence to: Dr Yao Wang, Department of General Surgery, Affiliated Hospital of Nantong University, 20 Xisi Road, Nantong, Jiangsu 226001, P.R. China

E-mail: wangyao12274@163.com

${ }^{*}$ Contributed equally

Key words: hepatocellular carcinoma, fibrinogen $\mathrm{C}$ domaincontaining 1, tissue microarray immunohistochemistry, biomarker, prognosis
HCC. Hence, FIBCD1 may be a novel biomarker for prognosis evaluation of HCC.

\section{Introduction}

Hepatocellular carcinoma (HCC) is the fourth most common type of malignancy and has the third highest rate of cancer-associated mortality of digestive system tumors worldwide, according to statistics from 2019 (1). The incidence of HCC is high in East Asia/Southeast Asia and Africa (2). Currently, the most common treatment for HCC is surgical resection, microwave ablation, transarterial chemoembolization, percutaneous radiofrequency ablation and liver transplantation (3). Sorafenib, the chemotherapy drug for HCC, is highly toxic $(3,4)$. The majority of patients already have advanced tumors when diagnosed (5). Tumor phenotype, genetic heterogeneity, multifocal occurrence due to intrahepatic metastasis and high recurrence and metastasis rates adversely affect the treatment and prognosis of patients with HCC $(6,7)$. Tumor biomarkers are being discovered at an increasing rate and may reveal disease mechanisms, aid in the diagnosis of cancer type and stage, facilitate monitoring of tumor progression, provide potential targets for novel therapies (8) and identify candidates for various treatments (9). Therefore, identification of novel biomarkers is essential for effective therapy in patients with liver cancer.

The Cancer Genome Atlas (TCGA) database has been used to identify novel protein molecules differentially expressed between cancerous and non-cancerous tissues (10). Fibrinogen $\mathrm{C}$ domain-containing 1 (FIBCD1) is a protein belonging to the fibrinogen-related domain (FReD) superfamily. To date, 541 FReDs have been found in mammals, 21 of which have also been identified in humans $(11,12)$. The FIBCD1 protein is made up of 461 amino acids (13) and is an acetyl receptor that combines with the acetyl sites of chitin at the FReD (14). The FReD superfamily consists mainly of soluble proteins and is widely distributed (15). FIBCD1 was initially found to be mainly present in epithelial cells in the intestine and salivary gland ducts (16).

FIBCD1 is highly-expressed in certain digestive system tumors, but its expression pattern in HCC has not been 
investigated yet. The role of FIBCD1 expression in the prognosis of HCC can be explored in bioinformatics analysis databases, such as TCGA or Oncomine. However, for clinical work in a hospital, fresh tissues are less common than pathological paraffin tissues, which are easier to store and manipulate. Thus, immunohistochemistry (IHC) for protein level detection is conducive to clinical research and further application (17). In the present study, bioinformatics tools and tissue microarray (TMA)-IHC were used to analyze FIBCD1 expression in $\mathrm{HCC}$ and normal samples. Associations between FIBCD1 and the clinicopathological and prognostic aspects of HCC were also examined.

\section{Materials and methods}

Bioinformatics analysis using the Oncomine database. The Oncomine database (http://www.oncomine.org) is currently the world's largest oncogene chip database and integrated data mining platform. The database has a high number of gene expression datasets and sample data from a large number of cancer tissues and normal tissues $(18,19)$. In the present study, the Oncomine database was used to evaluate FIBCD1 mRNA expression in $\mathrm{HCC}$ samples at a threshold of $\mathrm{P}<0.05$. 'FIBCD1,' 'mRNA,' 'HCC' and 'cancer vs. normal analysis' were the search queries used to obtain data. Two analyses from Wurmbach et al (20) were obtained, including 'Liver Cancer Precursor' and 'Liver Cell Dysplasia vs. Normal' (cirrhotic tissues, $n=13$; dysplastic nodules, $n=17$; HCCs, $n=35$; normal tissues, $\mathrm{n}=10$ ).

Tumor specimens and clinicopathological information. The present study was approved by the Human Research Ethics Committee at the Affiliated Hospital of Nantong University (Nantong, China). All experimental methods and related protocols were performed in accordance with the regulations of the Affiliated Hospital of Nantong University. All participating patients provided written informed consent for use of their tissues and for the publication of the present study. Formalin-fixed, paraffin-embedded tumor samples from 563 patients (range, 23-79 years), including 495 samples from patients with primary HCC, 32 chronic hepatitis tissues, 14 hepatic cavernous hemangioma tissues and 22 liver cirrhosis samples were collected. The tumor samples were matched with 495 peritumoral tissues (adjacent normal tissues; $>2 \mathrm{~cm}$ from the tumors' edges). These 563 patients underwent surgery at the Affiliated Hospital of Nantong University between January 2005 and December 2007. Clinical information, including sex, age, tumor diameter, $\alpha$-fetoprotein (AFP), tumor number, tumor node metastasis (TNM) stage, degree of differentiation, hepatitis B virus infection, vascular invasion and liver cirrhosis, was recorded. AFP is mainly synthesized in the liver of rodents and human embryos (21) and is the most specific marker of primary liver cancer (22). Disease stage was determined according to the 8th edition of the TNM Classification of Malignant Tumors guidelines (23). The period from diagnosis until death (from HCC only) was defined as overall survival (OS). The longest follow-up period was 99 months and 343 patients died during the study. None of these patients underwent any preoperative radiotherapy, chemotherapy or other special treatment for cancer.
$R T-q P C R$. Total RNA was extracted from 35 pairs of fresh-frozen tissues (tumor and adjacent normal tissues) collected from 35 patients ( 25 males and 10 females; range, $42-71$ years) who provided written informed consent for use of their tissues with HCC, from July to December in 2017, at the Affiliated Hospital of Nantong University. An RNeasy Mini kit and QiaShredders (Qiagen, Ltd.) were applied to isolate and purify total RNA from the tissues. In accordance with the manufacturer's protocol, cDNA was generated from total RNA using a reverse transcription kit (RevertAid Reverse Transcriptase RT kit; cat. no. K1691; Fermentas; Thermo Fisher Scientific, Inc.). qPCR was performed using the QuantiTect SYBR-Green PCR mixture on a Bio-Rad iCycler (Bio-Rad Laboratories, Inc.). The primer sequences for FIBCD1 were as follows: Forward, 5'-GTGTGGGGTTCC GTTCTC-3' and reverse, 5'-CCAGTGGTGCCAAGTCAA-3'. 18S rRNA (Thermo Fisher Scientific, Inc.) was used as the endogenous control and the primer sequences are as follows: Forward, 5'-TGCAGCGCACCGATGG-3' and reverse, 5'-GAG GTTGGTGAGGGAGATCG-3'. The thermocycling conditions were as follows: Initial denaturation at $95^{\circ} \mathrm{C}$ for $6 \mathrm{~min}$, followed by 35 cycles of $30 \mathrm{sec}$ at $95^{\circ} \mathrm{C}$ and $1 \mathrm{~min}$ at $60^{\circ} \mathrm{C}$. The levels of FIBCD1 mRNA were analyzed using the $2^{-\Delta \Delta \mathrm{Cq}}$ method (24). All experiments were repeated 3 times.

TMAs and IHC. Core tissue biopsies $(0.2 \mathrm{~cm}$ in diameter) obtained from paraffin-embedded blocks were arranged in new paraffin blocks using a Tissue Microarray system (cat. no. UT06; Quick-Ray; UNITMA, Co., Ltd.). The samples were then sliced into $4-\mu \mathrm{m}$ wide sections for IHC analysis. The sections were stained with polyclonal rabbit anti-FIBCD1 antibody (1:100 dilution; Atlas antibodies AB; cat. no. HPA053898) overnight at $4^{\circ} \mathrm{C}$, and then incubated with biotinylated anti-rabbit secondary antibody (1:2,000 dilution; cat. no. ZDR-5306; OriGene Technologies, Inc.) for $2 \mathrm{~h}$ at room temperature.

The intensity and percentages of FIBCD1 staining on each chip were scored by 2 trained observers. The intensity scores were defined as: 0 , negative; 1 , weakly positive; 2 , moderately positive; and 3, strongly positive. Percentage scores of FIBCD1 positive staining were defined as $0-100 \%$. The final score was calculated as percentage score $\mathrm{x}$ intensity score. X-tile software v3.6.1 (25) was used to determine the cut-off point for FIBCD1 expression data. The point was identified based on the maximum $\chi^{2}$ value, which was estimated by log-rank $\chi^{2}$ statistics according to OS. A cut-off value score of 110 was used to define the expression level; 111-300 was regarded as high and 0-110 was low or none.

Expression of FIBCDI in various types of cancer in bioinformatics databases. Gene Expression Profiling Interactive Analysis (GEPIA) (http://gepia.cancer-pku.cn/ index.html), a novel interactive web server, can be used to analyze RNA sequencing expression data from 9,736 tumors and 8,587 normal samples from TCGA database and the Genotype Tissue Expression project with a standard processing pipeline (26). GEPIA offers customizable features such as tumor and normal differential expression models. Datasets containing samples of liver HCC (LIHC; tumor, $n=369$ and normal, $n=50$ ), lung adenocarcinoma (LUAD; tumor, $n=482$ 
Table I. Fibrinogen C domain-containing 1 expression in liver tissues from benign and malignant diseases.

\begin{tabular}{lrrr}
\hline Characteristics & $\mathrm{n}$ & Low or none expression, $\mathrm{n}(\%)$ & High expression, $\mathrm{n}(\%)$ \\
\hline Chronic hepatitis & 32 & $30(93.8)$ & $2(6.3)$ \\
Hepatic cavernous hemangioma & 14 & $13(92.9)$ & $1(7.1)$ \\
Liver cirrhosis & 22 & $19(86.4)$ & $3(13.6)$ \\
Hepatocellular carcionoma & 495 & $251(50.7)$ & $244(49.3)$ \\
Adjacent normal & 495 & $455(92.0)$ & $40(8.0)$
\end{tabular}

$\chi^{2}, 224.27 ; \mathrm{P}<0.001$.
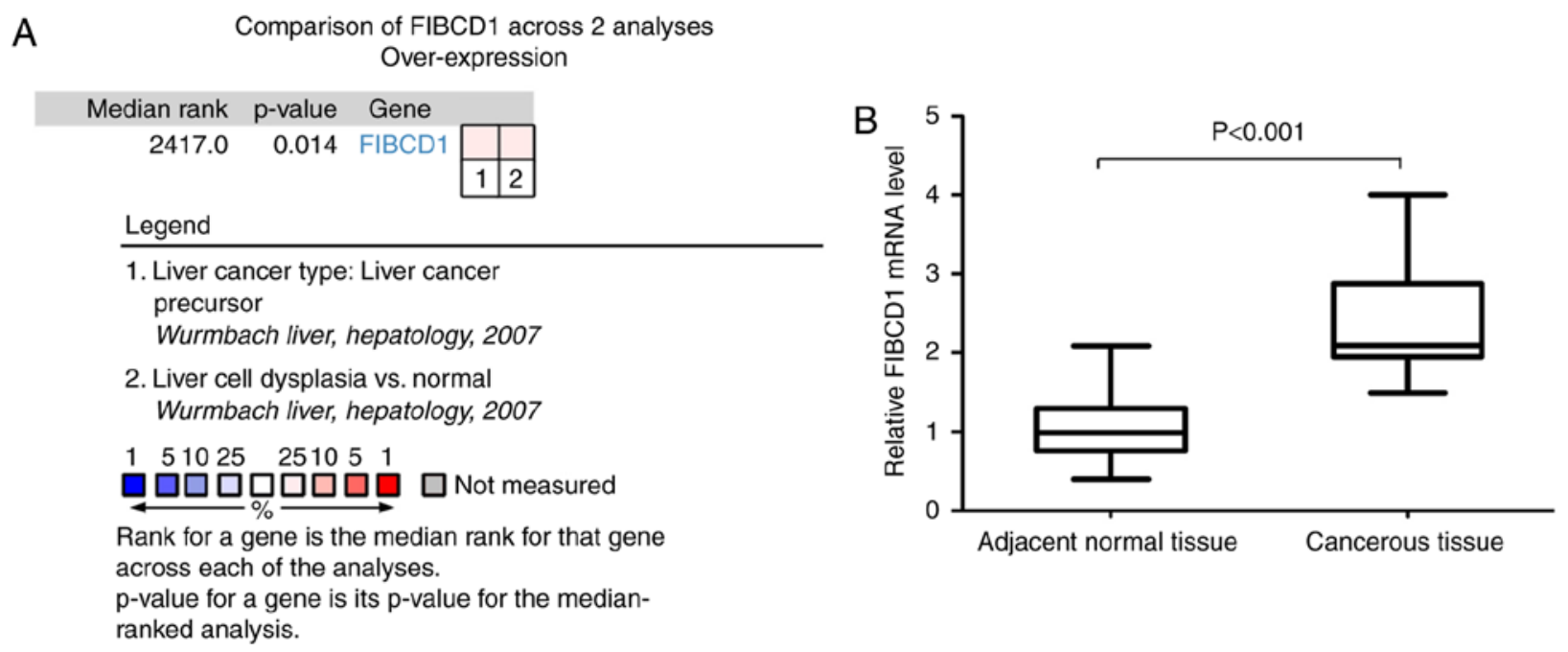

Figure 1. (A) FIBCD1 mRNA expression analysis using the Oncomine database for HCC. Oncomine map of FIBCD1 gene expression in HCC from 2 analyses is represented. (B) FIBCD1 mRNA expression in HCC and adjacent normal tissues. FIBCD1, fibrinogen C domain-containing 1, HCC, hepatocellular carcinoma.

A

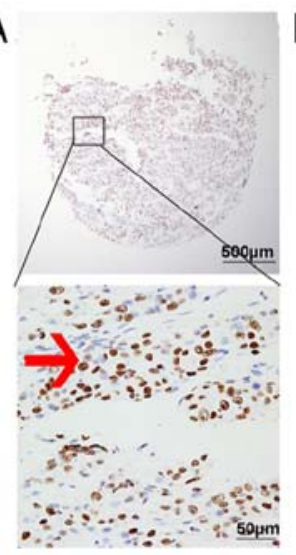

B

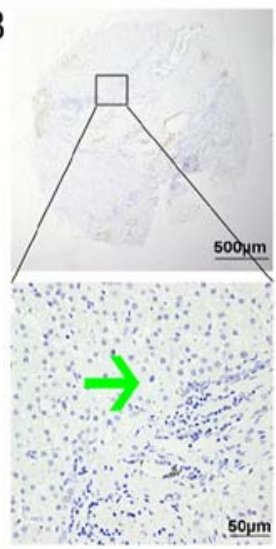

C

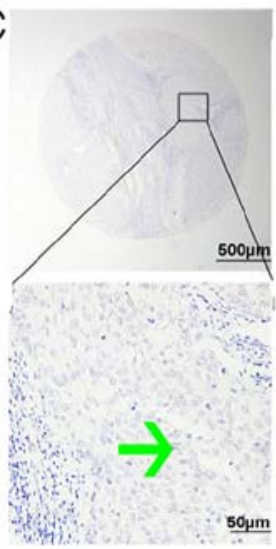

D

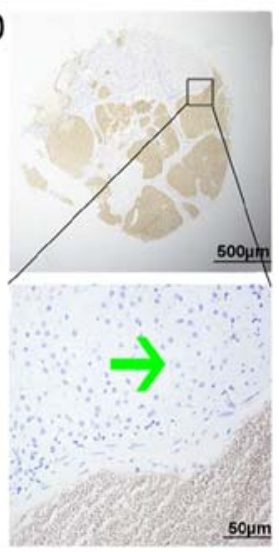

E

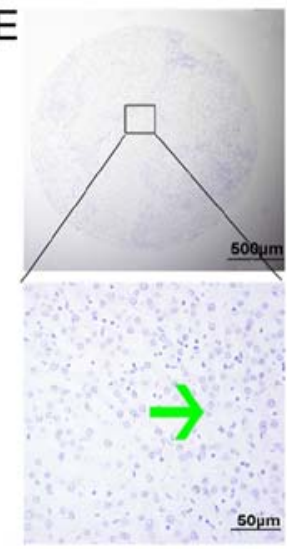

Figure 2. FIBCD1 protein expression in HCC and liver benign tissues as detected by tissue microarray-immunohistochemistry. (A) HCC with strong FIBCD1 expression. The red arrow indicates positive FIBCD1 protein expression in the nucleus of HCC cells. (B) Adjacent normal tissue with weak expression; (C) chronic hepatitis tissue with weak expression; (D) hepatic cavernous hemangioma tissue with weak expression; and (E) liver cirrhosis tissue with weak FIBCD1 expression. The green arrow indicates negative FIBCD1 protein expression in the nucleus of liver benign tissue cells in B, C, D and E. Magnifications: Upper, $\mathrm{x} 4$ and lower, $\mathrm{x} 40$. FIBCD1, fibrinogen $\mathrm{C}$ domain-containing 1; HCC, hepatocellular carcinoma.

and normal, $\mathrm{n}=59)$, mesothelioma (MESO; tumor, $\mathrm{n}=87$ ) and uveal melanoma (UVM; tumor, $n=79$ ) were investigated. In addition, the correlations of FIBCD1 expression and the expression of human hepatocyte growth factor (HGF) and recombinant heat shock $70 \mathrm{kDa}$ protein 4 (HSPA4) in liver tissues were further analyzed using Pearson's correlation coefficient test in the GEPIA database.

Kaplan-Meier plotter analysis. Kaplan-Meier plotter is an online survival analysis database (http://kmplot.com/analysis/) 
Table II. Association of FIBCD1 expression and clinicopathological characteristics of patients with hepatocellular carcinoma.

\begin{tabular}{|c|c|c|c|c|c|}
\hline \multirow[b]{2}{*}{ Characteristic } & \multirow[b]{2}{*}{ Cases, $\mathrm{n}$} & \multicolumn{2}{|c|}{ FIBCD1 expression, $\mathrm{n}(\%)$} & \multirow[b]{2}{*}{ Pearson $\chi^{2}$} & \multirow[b]{2}{*}{ P-value } \\
\hline & & Low or none & High & & \\
\hline Total patients & 495 & 251 & 244 & & \\
\hline Sex & & & & 0.092 & 0.761 \\
\hline Male & 139 & $72(51.8)$ & $67(48.2)$ & & \\
\hline Female & 356 & $179(50.3)$ & 177 (49.7) & & \\
\hline Age, years & & & & 0.030 & 0.862 \\
\hline$\leq 60$ & 379 & $193(50.9)$ & $186(49.1)$ & & \\
\hline$>60$ & 116 & $58(50.0)$ & $58(50.0)$ & & \\
\hline Tumor diameter, cm & & & & 9.564 & $0.002^{\mathrm{a}}$ \\
\hline$\leq 3$ & 256 & $147(57.4)$ & $109(42.6)$ & & \\
\hline$>3$ & 239 & $104(43.5)$ & $135(56.5)$ & & \\
\hline$\alpha$-fetoprotein, $\mu \mathrm{g} / 1$ & & & & 0.668 & 0.414 \\
\hline$\leq 400$ & 388 & 193 (49.7) & $195(50.3)$ & & \\
\hline$>400$ & 107 & $58(54.2)$ & $49(45.8)$ & & \\
\hline Tumor number & & & & 10.222 & $0.001^{\mathrm{a}}$ \\
\hline Solitary & 449 & $238(53.0)$ & $211(47.0)$ & & \\
\hline Multiple & 46 & $13(28.3)$ & $33(71.7)$ & & \\
\hline TNM stage & & & & 61.562 & $<0.001^{\mathrm{a}}$ \\
\hline I & 375 & $227(60.5)$ & $148(39.5)$ & & \\
\hline II & 74 & $18(24.3)$ & $56(75.7)$ & & \\
\hline III & 31 & $5(16.1)$ & $26(83.9)$ & & \\
\hline IV & 15 & $1(6.7)$ & $14(93.3)$ & & \\
\hline $\mathrm{T}$ & & & & 61.203 & $<0.001^{\mathrm{a}}$ \\
\hline 1 & 375 & $227(60.5)$ & $148(39.5)$ & & \\
\hline 2 & 74 & $18(24.3)$ & $56(75.7)$ & & \\
\hline 3 & 30 & $4(13.3)$ & $26(86.7)$ & & \\
\hline 4 & 16 & $2(12.5)$ & $14(87.5)$ & & \\
\hline $\mathrm{N}$ & & & & 9.883 & $0.002^{\mathrm{a}}$ \\
\hline 0 & 482 & $250(51.9)$ & $232(48.1)$ & & \\
\hline 1 & 13 & $1(7.7)$ & $12(92.3)$ & & \\
\hline M & & & & 5.196 & $0.023^{\mathrm{a}}$ \\
\hline 0 & 490 & $251(51.2)$ & $239(48.8)$ & & \\
\hline 1 & 5 & $0(0.0)$ & $5(100.0)$ & & \\
\hline \multicolumn{6}{|l|}{ Differentiation } \\
\hline Well & 124 & $70(56.5)$ & $54(43.5)$ & 13.754 & $0.003^{\mathrm{a}}$ \\
\hline Moderate & 287 & $152(53.0)$ & $135(47.0)$ & & \\
\hline Poor & 74 & $28(37.8)$ & $46(62.2)$ & & \\
\hline Others $^{\mathrm{b}}$ & 10 & $1(10.0)$ & $9(90.0)$ & & \\
\hline \multicolumn{6}{|c|}{ Hepatitis B virus infection } \\
\hline No & 268 & $126(47.0)$ & $142(53.0)$ & 3.187 & 0.074 \\
\hline Yes & 227 & $125(55.1)$ & $102(44.9)$ & & \\
\hline \multicolumn{6}{|l|}{ Vascular invasion } \\
\hline No & 451 & $241(53.4)$ & $210(46.6)$ & 15.126 & $<0.001^{\mathrm{a}}$ \\
\hline Yes & 44 & $10(22.7)$ & $34(77.3)$ & & \\
\hline \multicolumn{6}{|l|}{ Liver cirrhosis } \\
\hline No & 264 & $148(56.1)$ & $116(43.9)$ & 6.487 & $0.011^{\mathrm{a}}$ \\
\hline Yes & 231 & $102(44.6)$ & $128(55.4)$ & & \\
\hline
\end{tabular}

${ }^{\mathrm{a}} \mathrm{P}<0.05$; ${ }^{\mathrm{b}} \mathrm{Clear}$ cell type. FIBCD1, fibrinogen $\mathrm{C}$ domain-containing 1. 
Table III. Univariate and multivariable analysis of survival factors in patients with hepatocellular carcinoma.

\begin{tabular}{|c|c|c|c|c|c|c|c|c|}
\hline \multirow{3}{*}{$\begin{array}{l}\text { Variables } \\
\text { FIBCD1 expression, high vs. low or none }\end{array}$} & \multicolumn{4}{|c|}{ Univariate analysis } & \multicolumn{4}{|c|}{ Multivariate analysis } \\
\hline & \multirow{2}{*}{ HR } & \multirow{2}{*}{$\begin{array}{l}\text { P-value } \\
<0.001^{\mathrm{a}}\end{array}$} & \multicolumn{2}{|c|}{$95 \% \mathrm{CI}$} & \multirow{2}{*}{$\begin{array}{l}\mathrm{HR} \\
1.625\end{array}$} & \multirow{2}{*}{$\begin{array}{l}\text { P-value } \\
<0.001^{\mathrm{a}}\end{array}$} & \multicolumn{2}{|c|}{$95 \% \mathrm{CI}$} \\
\hline & & & 1.633 & 2.512 & & & 1.280 & 2.062 \\
\hline Age, $\leq 60$ vs. $>60$ years & 0.929 & 0.570 & 0.720 & 1.198 & & & & \\
\hline Sex, male vs. female & 0.921 & 0.484 & 0.730 & 1.161 & & & & \\
\hline Tumor diameter, $\leq 3$ vs. $>3 \mathrm{~cm}$ & 0.925 & 0.472 & 0.748 & 1.144 & & & & \\
\hline$\alpha$-fetoprotein, $\leq 400$ vs. $>400 \mu \mathrm{g} / 1$ & 0.927 & 0.570 & 0.715 & 1.203 & & & & \\
\hline Tumor number, solitary vs. multiple & 1.116 & 0.540 & 0.786 & 1.583 & & & & \\
\hline TNM stage, I vs. II vs. III vs. IV & 2.136 & $<0.001^{\mathrm{a}}$ & 1.869 & 2.440 & 0.316 & $0.003^{\mathrm{a}}$ & 0.147 & 0.679 \\
\hline T, 1 vs. 2 vs. 3 vs. 4 & 2.310 & $<0.001^{\mathrm{a}}$ & 2.010 & 2.656 & 4.822 & $<0.001^{\mathrm{a}}$ & 2.348 & 9.903 \\
\hline $\mathrm{N}, 0$ vs. 1 & 8.159 & $<0.001^{\mathrm{a}}$ & 4.561 & 14.595 & 3.296 & $0.014^{\mathrm{a}}$ & 1,276 & 8.511 \\
\hline M, 0 vs. 1 & 5.111 & $<0.001^{\mathrm{a}}$ & 2.093 & 12.485 & 0.454 & 0.163 & 0.149 & 1.379 \\
\hline $\begin{array}{l}\text { Differentiation, well vs. moderate vs. } \\
\text { poor vs. clear cell type }\end{array}$ & 1.065 & 0.426 & 0.912 & 1.242 & & & & \\
\hline Hepatitis B virus infection, no vs. yes & 1.056 & 0.614 & 0.854 & 1.306 & & & & \\
\hline Vascular invasion, no vs. yes & 5.669 & $<0.001^{\mathrm{a}}$ & 4.052 & 7.930 & 2.343 & $<0.001^{\mathrm{a}}$ & 1.468 & 3.739 \\
\hline Liver cirrhosis, no vs. yes & 1.290 & $0.020^{\mathrm{a}}$ & 1.042 & 1.598 & 1.203 & 0.104 & 0.962 & 1.504 \\
\hline
\end{tabular}

${ }^{\text {a }}<<0.05$. HR, hazard ratio; CI, confidence interval; FIBCD1, fibrinogen C domain-containing 1.

that includes transcriptomic data of 364 patients with liver cancer. This tool was used to analyze the prognostic significance of FIBCD1 using 4 as the cut-off value obtained from the database by selecting the 'auto select best cut-off' option for the dichotomization of FIBCD1 expression level.

Statistical analysis. All data were analyzed using SPSS software version 21.0 (IBM Corp.). The $\chi^{2}$ test was used to investigate the association between FIBCD1 expression and clinicopathological features. Wilcoxon signed-rank non-parametric test was used to analyze the difference between the paired HCC tissues and adjacent normal tissues. Kaplan-Meier curves and the log-rank test were used to assess the survival of patients with HCC. Univariate analysis and multivariate Cox regression was used to evaluate factors associated with prognosis. $\mathrm{P}<0.05$ was considered to indicate a statistically significant difference.

\section{Results}

FIBCDI mRNA and protein expression in HCC. The Oncomine database was utilized to assess FIBCD1 mRNA data. The mRNA levels of FIBCD1 were significantly increased in HCC in the 2 datasets (Fig. 1A). RT-qPCR revealed that the mean \pm SEM FIBCD1 mRNA expression in cancerous tissues and adjacent normal tissues was $2.37 \pm 0.10$ and $1.08 \pm 0.07$, respectively. The level of FIBCD1 mRNA expression in cancerous tissues was higher than that in adjacent normal tissues ( $\mathrm{P}<0.001$; Fig. 1B).

The TMA-IHC results showed that FIBCD1 is primarily localized to the nucleus of hepatocytes (Fig. 2). However, 3 chronic hepatitis tissues and 2 cirrhotic tissues showed positive FIBCD1 staining localized in the cytoplasm and cell membrane. However, this staining did not reach statistical significance, so only the tissues that were stained positively in the nucleus are discussed. Furthermore, FIBCD1 was expressed in 244/495 (49.3\%) HCC tissues compared with 40/495 (8.0\%) adjacent normal, 2/32 (6.3\%) chronic hepatitis, $1 / 14(7.1 \%)$ hepatic cavernous hemangioma and 3/22 (13.6\%) liver cirrhosis tissues (Fig. 2; Table I). High FIBCD1 protein expression was most frequent in HCC tissues $\left(\chi^{2}, 224.27\right.$; $\mathrm{P}<0.001)$.

FIBCD1 protein expression and clinical characteristics of patients with HCC. FIBCD1 protein expression level was associated with tumor diameter $(\mathrm{P}=0.002)$, tumor number $(\mathrm{P}=0.001)$, TNM stage $(\mathrm{P}<0.001)$, primary tumor $(\mathrm{T} ; \mathrm{P}<0.001)$, lymph node metastases $(\mathrm{N} ; \mathrm{P}=0.002)$, distant metastases $(\mathrm{M}$; $\mathrm{P}=0.023)$, differentiation degree $(\mathrm{P}=0.003)$, vascular invasion $(\mathrm{P}<0.001)$ and liver cirrhosis $(\mathrm{P}=0.011)$, but not with sex, age, AFP and hepatitis B virus infection $(\mathrm{P}>0.05$; Table II).

High FIBCD1 protein expression is associated with poor prognosis in patients with HCC. In univariate analysis, poor OS time was associated with high FIBCD1 expression (HR, 2.025; $\mathrm{P}<0.001)$, TNM stage (HR, 2.136; $\mathrm{P}<0.001)$, T (HR, 2.310; $\mathrm{P}<0.001), \mathrm{N}$ (HR, 8.159; $\mathrm{P}<0.001)$, M (HR, 5.111; $\mathrm{P}<0.001)$, vascular invasion $(\mathrm{HR}, 5.669 ; \mathrm{P}<0.001)$ and liver cirrhosis (HR, 1.290; $\mathrm{P}=0.020$ ) (Table III). In multivariate analysis, high FIBCD1 expression (HR, 1.625; $\mathrm{P}<0.001)$, TNM stage (HR, 0.316; $\mathrm{P}=0.003), \mathrm{T}(\mathrm{HR}, 4.822 ; \mathrm{P}<0.001), \mathrm{N}(\mathrm{HR}$, 3.296; $\mathrm{P}=0.014)$ and vascular invasion $(\mathrm{HR}, 2.343 ; \mathrm{P}<0.001)$ were independent prognostic factors (Table III).

Kaplan-Meier survival curve, based on the cohort of 563 patients from our institution, demonstrated that high FIBCD1 expression (Fig. 3A), TNM stage (Fig. 3B), T (Fig. 3C), N (Fig. 3D) and vascular invasion (Fig. 3E) were significantly 

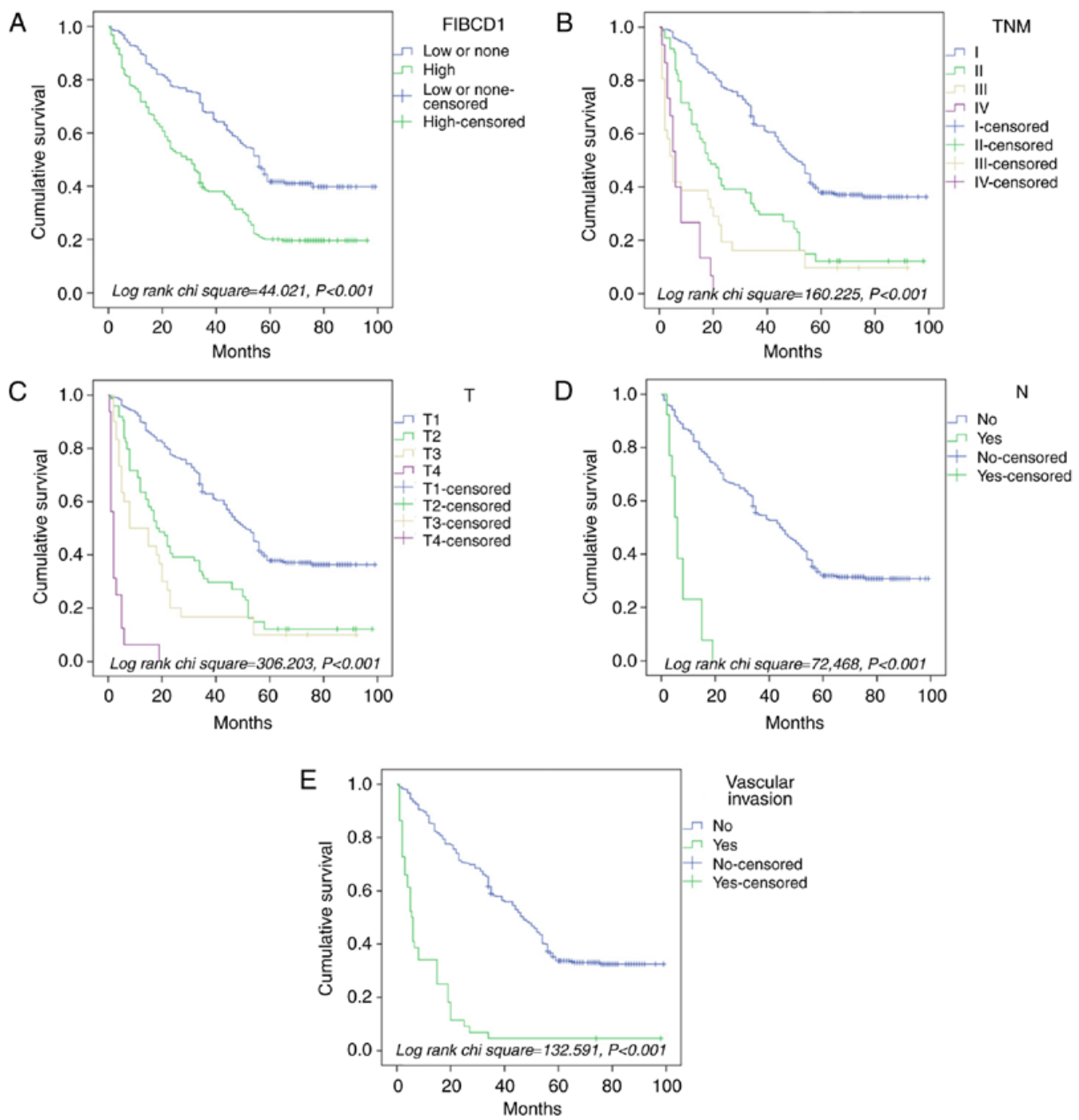

Figure 3. Kaplan-Meier survival curves and log-rank tests of patients with HCC. (A) Among HCC patients, the FIBCD1 low or none group had longer OS time than the FIBCD1 high group; (B) patients with early TNM stage had significantly longer OS time than those with advanced-stage TNM stage; (C) patients with low $\mathrm{T}$ stage had significantly longer OS time than those with high $\mathrm{T}$ stage; (D) patients with no lymph node metastasis had longer OS time than those with lymph node metastasis; (E) patients with no vascular invasion had longer OS time than those with vascular invasion. OS, overall survival; FIBCD1, fibrinogen C domain-containing 1; HCC, hepatocellular carcinoma.

associated with OS time. Hence, FIBCD1 expression may be a prognostic factor in HCC. The results from the Kaplan-Meier plotter database further demonstrated that patients with high FIBCD1 expression had a shorter OS time compared with those with low or no FIBCD1 expression ( $\mathrm{P}<0.001$; Fig. 4), consistent with the aforementioned results in Fig. 3.

Survival analysis of FIBCDI using the GEPIA database. The results obtained from the GEPIA database showed that FIBCD1 was expressed in different types of cancers, such as LIHC, LUAD, MESO and UVM. High FIBCD1 expression was found to result in a reduced OS time for patients with LIHC (HR, 1.60; $\mathrm{P}=0.016$ ), LUAD (HR,1.40; $\mathrm{P}=0.024)$, MESO (HR, 2.10; $\mathrm{P}=0.0025)$ and $\mathrm{UVM}\left(\mathrm{HR}, 6.90 ; \mathrm{P}=9.3 \times 10^{-5}\right)$ (Fig. 5).

Investigation of the correlation between the expression of FIBCD1, HGF and HSPA4 showed that the level FIBCD1 in liver tissues was positively correlated with $\mathrm{HGF}(\mathrm{r}=0.20$; $\mathrm{P}=0.041)$ and HSPA4 ( $\mathrm{r}=0.20 ; \mathrm{P}=0.04)$ (Fig. 6).

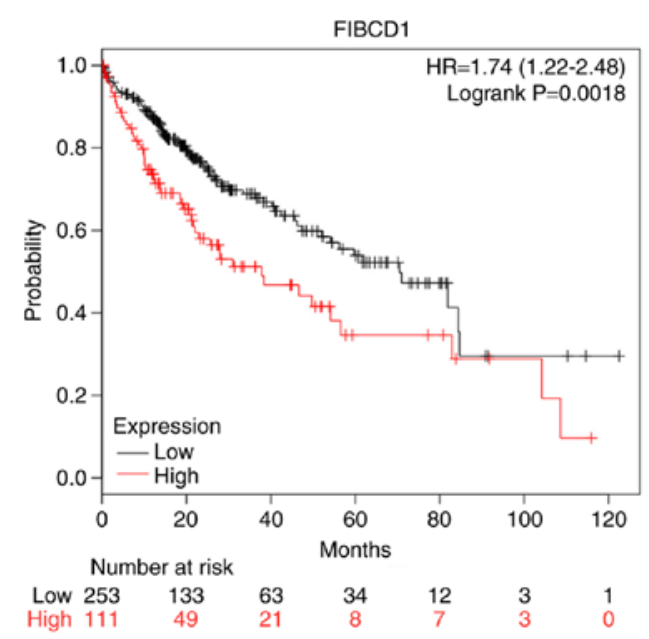

Figure 4. Kaplan-Meier Plotter analysis for OS of patients with hepatocellular carcinoma demonstrated that the FIBCD1-high group had significantly reduced OS time compared with FIBCD1-low or none groups $(n=364$; $\mathrm{P}=0.0018$ ). OS, overall survival; FIBCD1, fibrinogen $\mathrm{C}$ domain-containing 1. 

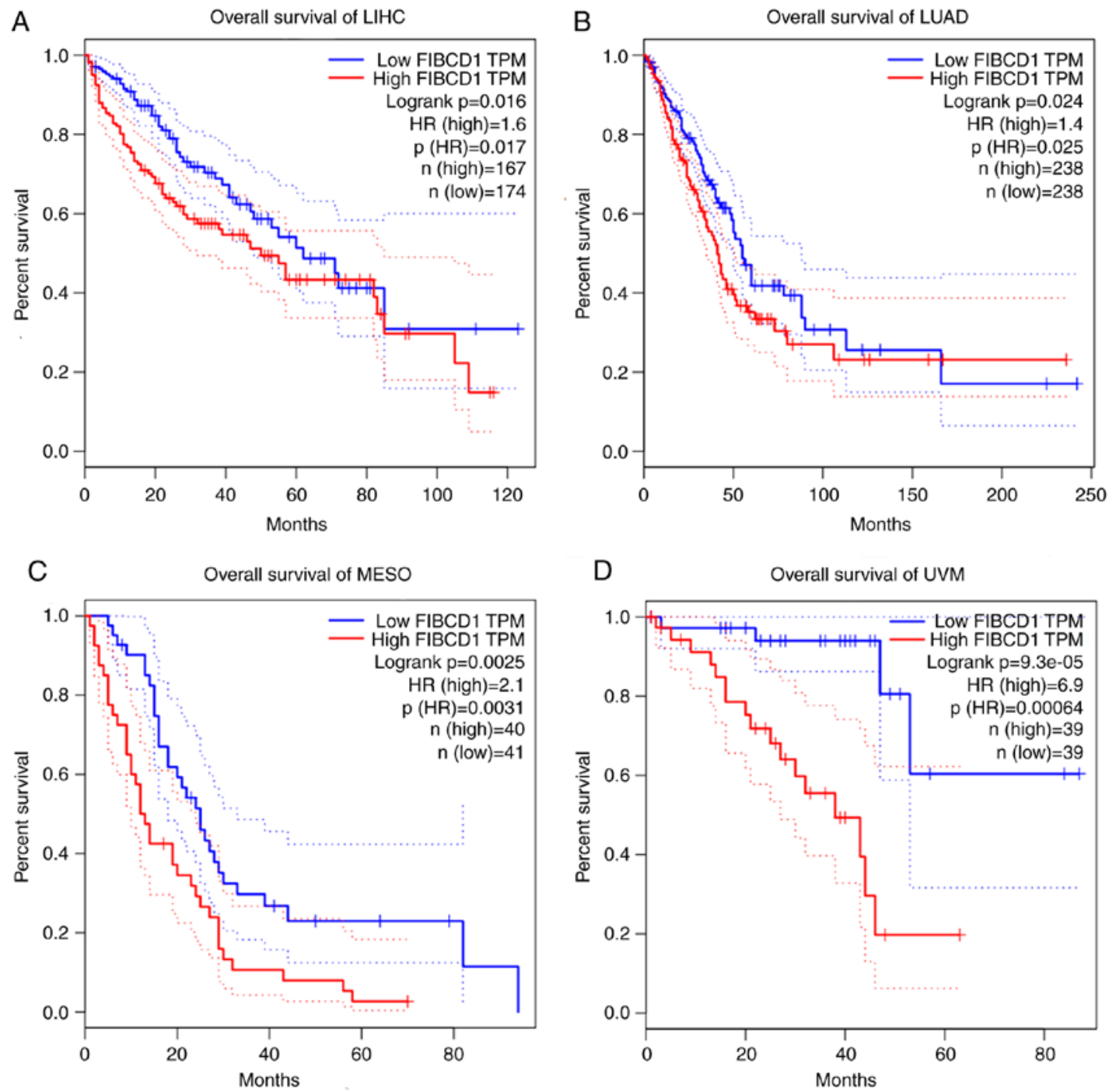

Figure 5. High FIBCD1 expression is associated with poor prognosis in different cancers. Overall survival rates in patients with (A) LIHC, (B) LUAD, (C) MESO and (D) UVM with high expression levels of FIBCD1 protein (red lines) were lower than in patients with low and no FIBCD1 expression (blue lines). LIHC, liver hepatocellular carcinoma; LUAD, lung adenocarcinoma; MESO, mesothelioma; UVM, uveal melanoma; FIBCD1, fibrinogen C domain-containing 1.
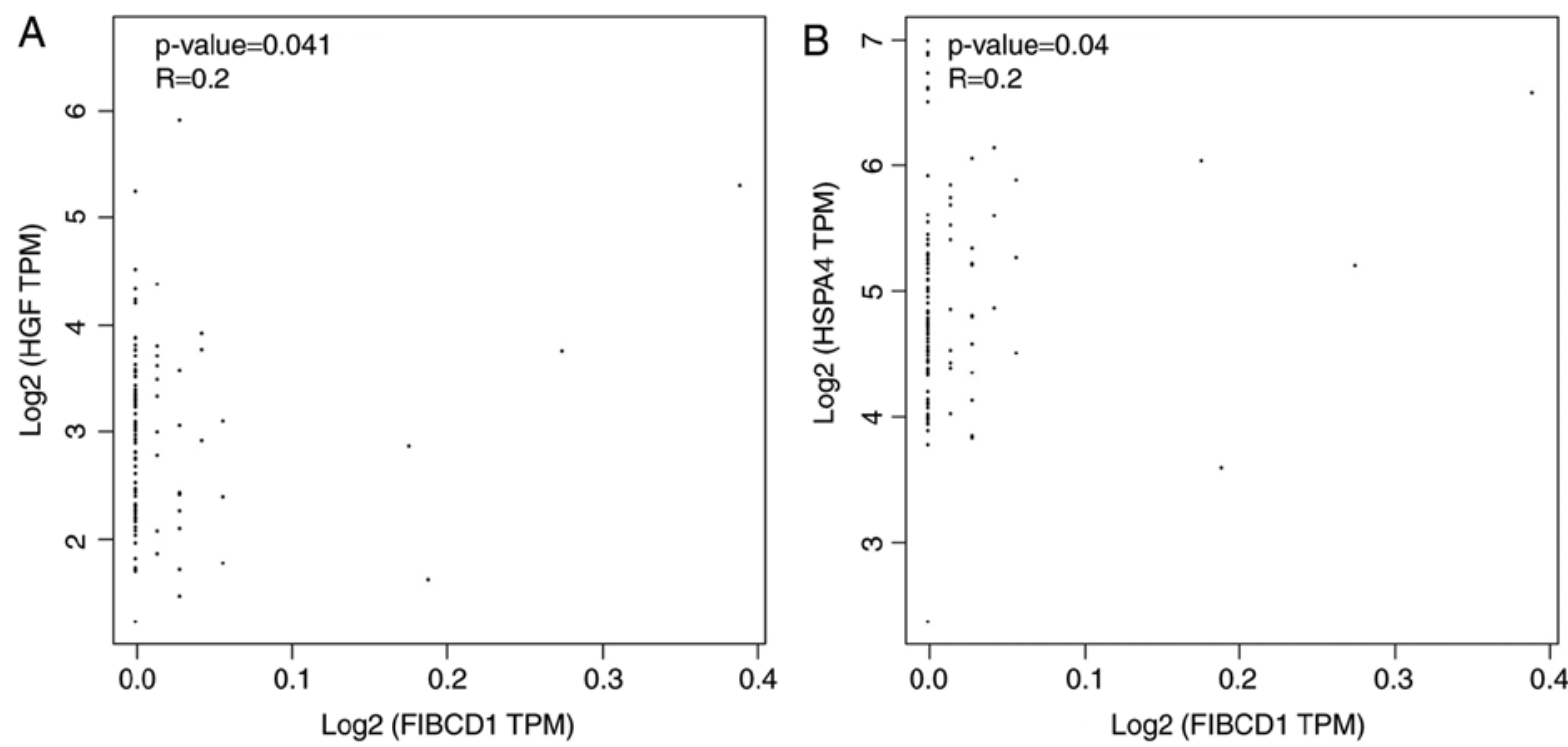

Figure 6. Correlation between FIBCD1 expression and (A) HGF and (B) HSPA4 expression in liver tissues. TPM, transcripts per kilobase million; FIBCD1, fibrinogen $\mathrm{C}$ domain-containing 1 ; HGF, human growth factor; HSPA4, heat shock protein family A member 4. 


\section{Discussion}

HCC is a common cancer in China; the incidence and mortality rates have increased annually (27). Similar to other tumors, the development of HCC is a multi-step process that is associated with oncogene activation, tumor suppressor gene inactivation, accumulation of mutations and epigenetic changes in regulatory genes (28). HCC is associated with many different gene mutations (29). Early diagnosis of HCC is difficult and most patients have advanced disease when they finally seek treatment (30). Targeted therapy is increasingly favored for liver cancer (31), and therapies that target epidermal growth factor receptor, vascular endothelial growth factor receptor, fatty acid binding protein 4 and ERK1/2 are being developed or tested to treat $\operatorname{HCC}(32,33)$.

With the rapid development of molecular biology techniques in recent years, research on tumor biomarkers of HCC has made some progress, but the treatment and prognosis for patients with HCC are not ideal. Thus, sensitive and effective HCC biomarkers should be developed. FIBCD1 may be one of these putative biomarkers.

The FIBCD1 gene, which is located on human chromosome $9 \mathrm{q} 34.1$, is next to the homologues that encode M- and L-ficolins $(34,35)$. FIBCD1 can be oligomerized and assembled into $250 \mathrm{kDa}$ tetramers with each chain containing a cytoplasmic tail, a transmembrane helix and an extracellular domain, consisting of a coiled region, a polycationic region and the C-terminal FReD, which assembles proteins into tetramers linked by disulfide bonds $(13,14)$. The FIBCD1 tetramer assembles in a calcium-dependent manner combined with acetylated compounds such as sialic acid and chitin (36).

FIBCD1 is widely distributed in human tissues and organs and may function as a pattern recognition receptor (PRR) (35). FIBCD1 was first found to bind to chitin, the second most abundant biopolymer in nature after cellulose (37), to stimulate and regulate the immune system in different ways, such as inducing cytokine production, promoting leukocyte recruitment, and activating macrophages (38). FIBCD1 was also the first membrane-binding FReD molecule found in vertebrates, and it mediates the degradation of acetylated components in vivo (13). In dermal tissues, FIBCD1 acts as a PRR for dendritic cells, macrophages, lymphocytes and other immune cells (39), and is also associated with dermatophyte infection (40). Furthermore, FIBCD1 plays a role against other bacterial infections, including pneumonia and urinary tract infections (35).

FIBCD1 is upregulated in the gastrointestinal tract compared with that in other organs within the body, such as the kidney, thymus, and the heart $(35,41)$. FIBCD1 upregulation predicts poor prognosis in patients with gastric cancer (41). FIBCD1 has high affinity for chitin fragments and can therefore control intestinal exposure to chitin and significantly affect immune responses to fungi and parasites (42). FIBCD1 is present in the apical intestinal epithelium and may play a large role in the innate immunity and homeostasis of the intestine (13).

FIBCD1 expression has recently been demonstrated in cells derived from all 3 germ layers, including lymph tissues, the thyroid gland and myocytes of the heart, and it is highly expressed in the respiratory, gastrointestinal and urogenital tracts (35). The expression pattern of FIBCD1, together with its known binding characteristics, supports its role in innate immunity (13). The liver is not only the largest digestive and metabolic organ of the body, but is also an important immune organ (43). HCC is the most common malignant tumor of the liver (44).

In the present study, the expression of FIBCD1 in HCC and the association with patient prognosis were investigated. The RT-qPCR and TMA-IHC analyses confirmed that mRNA and protein expression levels of FIBCD1 were increased in HCC compared with normal tissues. High FIBCD1 expression was associated with certain clinicopathological parameters, including large tumor diameter, tumor number, advanced TNM stage, degree of differentiation, vascular invasion and liver cirrhosis. High FIBCD1 expression, along with vascular invasion and TNM stage, predicts poor prognosis and increased mortality for patients with HCC. FIBCD1 mediates the endocytosis of intracellular binding ligands that are released into the surrounding environment after degradation; FIBCD1 is then simultaneously recycled back to the plasma membrane (14). FIBCD1 has 2 potential phosphorylation sites, including chondroitin and dermatan sulfate in its cytoplasmic domain (14). Thus, FIBCD1 may be a signaling protein, but its signal transduction pathway remains unclear. In the present study, the results obtained using the GEPIA database demonstrated that the correlations between FIBCD1 expression and HGF, and FIBCD1 expression and HSPA4 were positive. Activation of the HGF/c-Met axis facilitates the proliferation and migration of HCC cells (45). HSPA4 was found to be upregulated in HCC, and may be associated with the early recurrence and poor OS of HCC $(46,47)$. From the results of the current study, it can be inferred that high FIBCD1 expression may promote the occurrence and development of HCC, but understanding how it interacts with HGF and HSPA4 requires further investigation.

The present study has certain limitations. As the current study is retrospective, the sample size and quality of specimens was limited. Additionally, the detection methods used to determine FIBCD1 expression in HCC were limited as RT-qPCR and IHC may not be accurate and comprehensive. RNAscope in situ hybridization maybe more suitable for detecting FIBCD1 mRNA. Furthermore, the biological mechanisms of FIBCD1 action have not been studied in HCC. Future larger-scale studies with newer techniques for investigating FIBCD1 expression are required.

In summary, FIBCD1 expression is increased in HCC tissues. High FIBCD1 expression is associated with poor prognosis in patients with HCC. Hence, FIBCD1 has value as a prognostic predictor and a potential target for HCC therapy.

\section{Acknowledgements}

Not applicable.

\section{Funding}

The present study was supported by the Construction of Clinical Medical Center for tumor biological samples in Nantong (grant no. HS2016004). 


\section{Availability of data and materials}

The datasets used and/or analyzed during the current study are available from the corresponding author on reasonable request.

\section{Authors' contributions}

YW and MS performed data analyses and wrote the manuscript. JL, YL, CJ, HZ and WW contributed significantly to data analyses and manuscript revision. YW conceived and designed the study. All authors read and approved the final manuscript.

\section{Ethics approval and consent to participate}

The present study was approved by the Human Research Ethics Committee at the Affiliated Hospital of Nantong University (Nantong, China). All experimental methods and related protocols were performed according to the regulations of the Affiliated Hospital of Nantong University. Signed informed consent was obtained from the patients or their guardians.

\section{Patient consent for publication}

Not applicable.

\section{Competing interests}

The authors declare that they have no competing interests.

\section{References}

1. Siegel RL, Miller KD and Jemal A: Cancer statistics, 2019. CA Cancer J Clin 69: 7-34, 2019.

2. Liu KY, Wang LT, Hsu SH and Wang SN: Homeobox genes and hepatocellular carcinoma. Cancers (Basel) 11: pii: E621, 2019.

3. Xue F, Liu Y, Chu H, Wen Y, Yan L, Tang Q, Xiao E, Zhang D and Zhang H: eIF5A2 is an alternative pathway for cell proliferation in cetuximab-treated epithelial hepatocellular carcinoma. Am J Transl Res 8: 4670-4681, 2016.

4. Xue F, Liu Y, Zhang H, Wen Y, Yan L, Tang Q, Xiao E and Zhang D: Let-7a enhances the sensitivity of hepatocellular carcinoma cells to cetuximab by regulating STAT3 expression. Onco Targets Ther 9: 7253-7261, 2016.

5. Banini BA and Sanyal AJ: The use of cell free DNA in the diagnosis of HCC. Hepatoma Res 5: pii: 34, 2019.

6. Amicone L and Marchetti A: Microenvironment and tumor cells: Two targets for new molecular therapies of hepatocellular carcinoma. Transl Gastroenterol Hepatol 3: 24, 2018.

7. Waller LP, Deshpande V and Pyrsopoulos N: Hepatocellular carcinoma: A comprehensive review. World J Hepatol 7: 2648-2663, 2015.

8. Mordente A, Meucci E, Martorana GE and Silvestrini A: Cancer biomarkers discovery and validation: State of the art, problems and future perspectives. Adv Exp Med Biol 867: 9-26, 2015.

9. Cetin B, Gumusay O, Cengiz M and Ozet A: Advances of molecular targeted therapy in gastric cancer. J Gastrointest Cancer 47: 125-134, 2016.

10. Deng M, Brägelmann J, Schultze JL and Perner S: Web-TCGA: An online platform for integrated analysis of molecular cancer data sets. BMC Bioinformatics 17: 72, 2016.

11. Zuliani-Alvarez L and Midwood KS: Fibrinogen-related proteins in tissue repair: How a unique domain with a common structure controls diverse aspects of wound healing. Adv Wound Care (New Rochelle) 4: 273-285, 2015.

12. Thomsen T, Schlosser A, Holmskov U and Sorensen GL: Ficolins and FIBCD1: Soluble and membrane bound pattern recognition molecules with acetyl group selectivity. Mol Immunol 48: 369-381, 2011
13. Schlosser A, Thomsen T, Moeller JB, Nielsen O, Tornoe I, Mollenhauer J, Moestrup SK and Holmskov U: Characterization of FIBCD1 as an acetyl group-binding receptor that binds chitin. J Immunol 183: 3800-3809, 2009.

14. Shrive AK, Moeller JB, Burns I, Paterson JM, Shaw AJ, Schlosser A, Sorensen GL, Greenhough TJ and Holmskov U: Crystal structure of the tetrameric fibrinogen-like recognition domain of fibrinogen $\mathrm{C}$ domain containing 1 (FIBCD1) protein. J Biol Chem 289: 2880-2887, 2014.

15. Doolittle RF, McNamara K and Lin K: Correlating structure and function during the evolution of fibrinogen-related domains. Protein Sci 21: 1808-1823, 2012.

16. Rossi V, Bally I, Thielens NM, Esser AF and Arlaud GJ: Baculovirus-mediated expression of truncated modular fragments from the catalytic region of human complement serine protease C1s. Evidence for the involvement of both complement control protein modules in the recognition of the $\mathrm{C} 4$ protein substrate. J Biol Chem 273: 1232-1239, 1998.

17. Peschl P, Ramberger M, Höftberger R, Jöhrer K, Baumann M, Rostásy K and Reindl M: Methodological challenges in protein microarray and immunohistochemistry for the discovery of novel autoantibodies in paediatric acute disseminated encephalomyelitis. Int J Mol Sci 18: pii: E679, 2017.

18. Rhodes DR, Kalyana-Sundaram S, Mahavisno V, Varambally R, Yu J, Briggs BB, Barrette TR, Anstet MJ, Kincead-Beal C, Kulkarni P, et al: Oncomine 3.0: Genes, pathways, and networks in a collection of 18,000 cancer gene expression profiles. Neoplasia 9: 166-180, 2007.

19. Cao T, Pan W, Sun X and Shen H: Increased expression of TET3 predicts unfavorable prognosis in patients with ovarian cancer-a bioinformatics integrative analysis. J Ovarian Res 12: 101, 2019.

20. Wurmbach E, Chen YB, Khitrov G, Zhang W, Roayaie S, Schwartz M, Fiel I, Thung S, Mazzaferro V, Bruix J, et al: Genome-wide molecular profiles of HCV-induced dysplasia and hepatocellular carcinoma. Hepatology 45: 938-947, 2007.

21. Terentiev AA and Moldogazieva NT: Alpha-fetoprotein: A renaissance. Tumour Biol 34: 2075-2091, 2013.

22. Sauzay C, Petit A, Bourgeois AM, Barbare JC, Chauffert B, Galmiche A and Houessinon A: Alpha-foetoprotein (AFP): A multi-purpose marker in hepatocellular carcinoma. Clin Chim Acta 463: 39-44, 2016.

23. Abdel-Rahman O: Assessment of the discriminating value of the 8th AJCC stage grouping for hepatocellular carcinoma. HPB (Oxford) 20: 41-48, 2018

24. Livak KJ and Schmittgen TD: Analysis of relative gene expression data using real-time quantitative PCR and the 2(-Delta Delta C(T)) method. Methods 25: 402-408, 2001.

25. Camp RL, Dolled-Filhart M and Rimm DL: X-tile: A new bio-informatics tool for biomarker assessment and outcome-based cut-point optimization. Clin Cancer Res 10: 7252-7259, 2004.

26. Tang Z, Li C, Kang B, Gao G, Li C and Zhang Z: GEPIA: A web server for cancer and normal gene expression profiling and interactive analyses. Nucleic Acids Res 45 (W1): W98-W102, 2017.

27. Parikh ND, Fu S, Rao H, Yang M, Li Y, Powell C, Wu E, Lin A, Xing B, Wei L and Lok ASF: Risk assessment of hepatocellular carcinoma in patients with hepatitis C in China and the USA. Dig Dis Sci 62: 3243-3253, 2017.

28. Kanda M, Sugimoto H and Kodera Y: Genetic and epigenetic aspects of initiation and progression of hepatocellular carcinoma. World J Gastroenterol 21: 10584-10597, 2015.

29. Hu J and Gao DZ: Distinction immune genes of hepatitis-induced heptatocellular carcinoma. Bioinformatics 28: 3191-3194, 2012.

30. Finn RS: Advanced HCC: Emerging molecular therapies. Minerva Gastroenterol Dietol 58: 25-34, 2012.

31. Marquardt JU, Galle PR and Teufel A: Molecular diagnosis and therapy of hepatocellular carcinoma (HCC): An emerging field for advanced technologies. J Hepatol 56: 267-275, 2012.

32. Wang K, Fan Y, Chen G, Wang Z, Kong D and Zhang P: MEK-ERK inhibition potentiates WAY-600-induced anti-cancer efficiency in preclinical hepatocellular carcinoma (HCC) models. Biochem Biophys Res Commun 474: 330-337, 2016.

33. Zhong CQ, Zhang XP, Ma N, Zhang EB, Li JJ, Jiang YB, Gao YZ, Yuan YM, Lan SQ, Xie D and Cheng SQ: FABP4 suppresses proliferation and invasion of hepatocellular carcinoma cells and predicts a poor prognosis for hepatocellular carcinoma. Cancer Med 7: 2629-2640, 2018.

34. Thomsen T, Moeller JB, Schlosser A, Sorensen GL, Moestrup SK, Palaniyar N, Wallis R, Mollenhauer J and Holmskov U: The recognition unit of FIBCD1 organizes into a noncovalently linked tetrameric structure and uses a hydrophobic funnel (S1) for acetyl group recognition. J Biol Chem 285: 1229-1238, 2010. 
35. von Huth S, Moeller JB, Schlosser A, Marcussen N, Nielsen O, Nielsen V, Sorensen GL and Holmskov U: Immunohistochemical localization of fibrinogen $\mathrm{C}$ domain containing 1 on epithelial and mucosal surfaces in human tissues. J Histochem Cytochem 66: 85-97, 2018.

36. Bueter CL, Specht CA and Levitz SM: Innate sensing of chitin and chitosan. PLoS Pathog 9: e1003080, 2013.

37. Kurita K: Chitin and chitosan: Functional biopolymers from marine crustaceans. Mar Biotechnol (NY) 8: 203-226, 2006.

38. Elieh Ali Komi D, Sharma L and Dela Cruz CS: Chitin and its effects on inflammatory and immune responses. Clin Rev Allergy Immunol 54: 213-223, 2018.

39. Tong PL, Roediger B, Kolesnikoff N, Biro M, Tay SS, Jain R, Shaw LE, Grimbaldeston MA and Weninger W: The skin immune atlas: three-dimensional analysis of cutaneous leukocyte subsets by multiphoton microscopy. J Invest Dermatol 135: 84-93, 2015.

40. Abdel-Rahman SM: Genetic predictors of susceptibility to dermatophytoses. Mycopathologia 182: 67-76, 2017.

41. Jiang C, Zhu J, Zhou P, Zhu H, Wang W, Jin Q and Li P: Overexpression of FIBCD1 is predictive of poor prognosis in gastric cancer. Am J Clin Pathol 149: 474-483, 2018.

42. Garlatti V, Belloy N, Martin L, Lacroix M, Matsushita M, Endo Y, Fujita T, Fontecilla-Camps JC, Arlaud GJ, Thielens NM and Gaboriaud C: Structural insights into the innate immune recognition specificities of L- and H-ficolins. EMBO J 26: 623-633, 2007.

43. Zhang Q, He Y, Luo N, Patel SJ, Han Y, Gao R, Modak M, Carotta S, Haslinger C, Kind D, et al: Landscape and dynamics of single immune cells in hepatocellular carcinoma. Cell 179: 829-845 e20, 2019.
44. Wang Y, Liu X, Liu G, Wang X, Hu R and Liang X: PIG11 over-expression predicts good prognosis and induces HepG2 cell apoptosis via reactive oxygen species-dependent mitochondrial pathway. Biomed Pharmacother 108: 435-442, 2018.

45. Liu Y, Tan J, Ou S, Chen J and Chen L: MicroRNA-101-3p suppresses proliferation and migration in hepatocellular carcinoma by targeting the HGF/c-Met pathway. Invest New Drugs, Mar 30, 2019 (Epub ahead of print).

46. Ma C, Xu T, Sun X, Zhang S, Liu S, Fan S, Lei C, Tang F, Zhai C, $\mathrm{Li} \mathrm{C}$, et al: Network pharmacology and bioinformatics approach reveals the therapeutic mechanism of action of baicalein in hepatocellular carcinoma. Evid Based Complement Alternat Med 2019: 7518374, 2019.

47. Yang Z, Zhuang L, Szatmary P, Wen L, Sun H, Lu Y, Xu Q and Chen X: Upregulation of heat shock proteins (HSPA12A, HSP90B1, HSPA4, HSPA5 and HSPA6) in tumour tissues is associated with poor outcomes from HBV-related early-stage hepatocellular carcinoma. Int J Med Sci 12: 256-263, 2015.

This work is licensed under a Creative Common Attribution-NonCommercial-NoDerivatives 4.0 International (CC BY-NC-ND 4.0) License. 